\title{
KARAKTERISTIK MASYARAKAT SUB DAS PENGKOL DALAM KAITANNYA DENGAN PENGELOLAAN DAS \\ (Studi Kasus di Sub DAS Pengkol, Kabupaten Wonogiri, Jawa Tengah) (Characteristics of Society Pengkol Sub-Watershed in Relation with Watershed Management (Case study in Pengkol Sub-Watershed, Wonogiri Regency, Central Java))
}

\author{
Nur Ainun Jariyah ${ }^{1}$ \\ ${ }^{1}$ Balai Penelitian Teknologi Kehutanan Pengelolaan Daerah Aliran Sungai. \\ Jl. A. Yani PO Box 295 Pabelan. Telepon/Fax.: (+62 271) 716709/716959 \\ E-mail: nurainun_2513@yahoo.co.id \\ Diterima 8 Juli 2013, direvisi 3 Februari 2014, disetujui 21 Februari 2014
}

\begin{abstract}
Pengkol Sub-watershed is part of the Keduang watershed, where is one of the sub-watersheds that contribute to erosion and sedimentation in the Gadjah Mungkur reservoir. Base on the problems that exist in the upstream, the aims of study to investigate the characteristics of upstream social culture of the community in relation to watershed management. The research was conducted in the Pengkol sub-watershed in Wonogiri district, represented by the area upstream, midstream and downstream. This activity is a qualitative research. Data taken include primary data and secondary data. The parameters are taken the identity of respondents, population density, culture, land and institutional dependency. Data is collected by conducting interviews with questionnaire and indepth interviews with key person. Random selection of respondents drawn proportionately adjusted for the purpose of research. Data analysis was done by descriptive qualitative. The conclusion of this study were (1) Characteristics of upstream communities are generally farmers with age is still productive. Farmers are aware of the benefits and impacts of not implement soil conservation, (2) In general, farmers have more than one of field land and planted crops intercropping, medicinal spices and woody plants, (3) family income the three villages is above in Living Needs, (4) Need for better coaching and structured to build communities upstream with community, (5) It needs a reward for people who havepracticed soil conservation activities in upstream.
\end{abstract}

Keywords: Characters of farmers, watershed management, Pengkol Sub-watershed, conservation

ABSTRAK

Sub DAS Pengkol merupakan bagian dari DAS Keduang, yang merupakan salah satu sub DAS penyumbang erosi dan sedimentasi di Waduk Gadjah Mungkur. Berdasarkan permasalahan-permasalahan yang ada di daerah hulu, maka kajian ini bertujuan untuk mengetahui karakteristik sosial budaya masyarakat hulu dalam kaitannya dengan pengelolaan DAS. Penelitian ini dilakukan di wilayah Sub DAS Pengkol di Kabupaten Wonogiri, diwakili oleh wilayah hulu, tengah dan hilir. Data yang diambil meliputi data primer dan data sekunder dengan parameter identitas responden, kepadatan penduduk, budaya, ketergantungan lahan dan kelembagaan. Pengambilan data menggunakan teknik wawancara dengan panduan kuesioner dan wawancara mendalam kepada tokoh kunci. Pemilihan responden dilakukan secara acak proporsional sesuai tujuan penelitian, dan analisis data menggunakan metode deskriptif kualitatif. Hasil penelitian menunjukkan bahwa (1) Karakteristik masyarakat hulu pada umumnya adalah petani dengan umur masih produktif. Petani sudah paham akan manfaat dan dampak konservasi tanah apabila tidak dilakukan, (2) Pada umumnya petani mempunyai lahan lebih dari satu bidang dan ditanami tanaman tumpangsari, empon-empon dan tanaman berkayu, (3) Pendapatan keluarga ketiga desa lebih besar dari Kebutuhan Hidup Layak, (4) Perlu adanya pembinaan yang lebih baik dan terstruktur untuk membangun daerah hulu bersama masyarakat, (5) Perlu adanya reward untuk masyarakat hulu yang telah melakukan kegiatan konservasi tanah.

Kata kunci: Karakter petani, managemen DAS, Sub DAS Pengkol, konservasi 


\section{PENDAHULUAN}

Sub DAS Pengkol merupakan bagian dari DAS Keduang, yang merupakan salah satu sub DAS penyumbang terbesar erosi dan sedimentasi di Waduk Gadjah Mungkur. Sedimentasi menyebabkan pendangkalan di Waduk Gadjah Mungkur, dimana waduk tersebut berfungsi sebagai penampung air dari hulu, dan pengendali banjir Sungai Bengawan Solo. Perkembangan terakhir diperkirakan umur pakai Waduk Gadjah Mungkur tinggal 10-15 tahun lagi, menurut perencanaan umur pakainya adalah 100 tahun (http://epriant. blogspot.com). Pendangkalan tersebut dikhawatirkan tidak akan mampu menampung air di Sungai Bengawan Solo.

Erosi dan sedimentasi tersebut dimungkinkan karena adanya perubahan fungsi lahan sehingga dapat mengganggu kehidupan masyarakat. Ada tiga hal utama yang dapat menyebabkan Daerah Aliran Sungai di Indonesia terdegradasi. Penyebab utama adalah akibat aktifitas manusia yang meliputi penebangan hutan yang dilakukan secara illegal, kebakaran hutan, perambahan hutan, eksploitasi hutan dan lahan yang berlebihan dan pemanfaatan lahan yang tidak menerapkan konservasi tanah dan air (http:/ / www.scbfwm.org).

Sheng (1986) dalam Paimin dkk (2006) menyatakan bahwa permasalahan DAS tumbuh seiring dengan pertambahan penduduk dan waktu. DAS sangat dipengaruhi oleh bagian hulu, kondisi biofisik daerah tangkapan dan daerah resapan air. Pada umumnya kondisi di daerah hulu rawan terhadap gangguan manusia (www.bappenas.go.id). Menurut Atmojo (2009) pengelolaan DAS bagian hulu sering menjadi fokus perhatian, mengingat kawasan DAS bagian hulu dan hilir mempunyai keterkaitan biofisik melalui daur hidrologi, sehingga kesalahan penggunaan lahan daerah hulu akan berdampak pada masyarakat di daerah hilir.

Pola usaha tani hulu DAS sebagian besar dilakukan oleh petani lahan kering yang tidak terlepas dari keterbatasan kondisi sosial ekonomi, sumber daya, dan kemampuan/keterampilan, sehingga tidak mampu melakukan pengolahan lahan sesuai daya dukung lahan, serta tidak menerapkan teknik konservasi tanah dan air dengan baik (http://www.scbfwm.org). Melihat hal tersebut jelas bahwa kondisi sosial ekonomi masyarakat khususnya daerah hulu sangat berpengaruh terhadap kondisi DAS. Semakin intensif pengelolaan lahan daerah hulu akan mempengaruhi kondisi daerah hilir. Kajian ini bertujuan untuk mengetahui karakteristik sosial budaya masyarakat hulu dalam kaitannya dengan pengelolaan DAS. Diharapkan dari kajian ini dapat memberikan bahan masukan pemegang kebijakan untuk mengatur daerah hulu.

\section{METODE PENELITIAN}

\section{A. Lokasi Penelitian}

Penelitian ini dilakukan di wilayah Sub DAS Pengkol di Kabupaten Wonogiri. Untuk memperoleh gambaran yang jelas dalam menjawab tujuan, setiap lokasi penelitian dibedakan menjadi hulu, tengah dan hilir. Lokasi penelitian tersebut dilakukan di Desa Setren, Kecamatan Slogohimo mewakili hulu, wilayah tengah diwakili oleh Desa Karang, Kecamatan Slogohimo dan wilayah hilir diwakili oleh Desa Sugihan, Kecamatan Jatiroto.

Sub DAS Pengkol mempunyai luas 3.057,59 ha, dan merupakan bagian dari Sub DAS Keduang. Lokasi penelitian sub DAS Pengkol dapat dilihat pada Gambar 1.

\section{B. Pengumpulan Data}

Data penelitian meliputi data primer dan data sekunder. Sebagai parameter penelitian adalah identitas responden, kepadatan penduduk, budaya, ketergantungan terhadap lahan dan kelembagaan.

Pengambilan data dilakukan menggunakan metode wawancara dengan panduan kuesioner dan wawancara mendalam kepada tokoh kunci. Responden penelitian adalah petani pemilik lahan tegal, dipilih secara acak proporsional sesuai tujuan penelitian, yaitu sebanyak 30 orang di masing-masing wilayah hulu, tengah dan hilir, sehingga jumlah responden adalah 90 orang. Pengumpulan data sekunder dilakukan di instansi terkait seperti Balai Sungai, Kementrian Pekerjaan Umum, Dinas Pertanian, Dinas Kehutanan, Kesbanglinmas, dan BPS.

\section{Analisis Data}

Analisis data dilakukan menggunakan metode deskriptif kualitatif. Deskriptif kualitatif adalah mengolah dan menganalisis data-data yang terkumpul menjadi data yang sistematik, teratur, terstruktur dan mempunyai makna (Sarwono, 2006). 


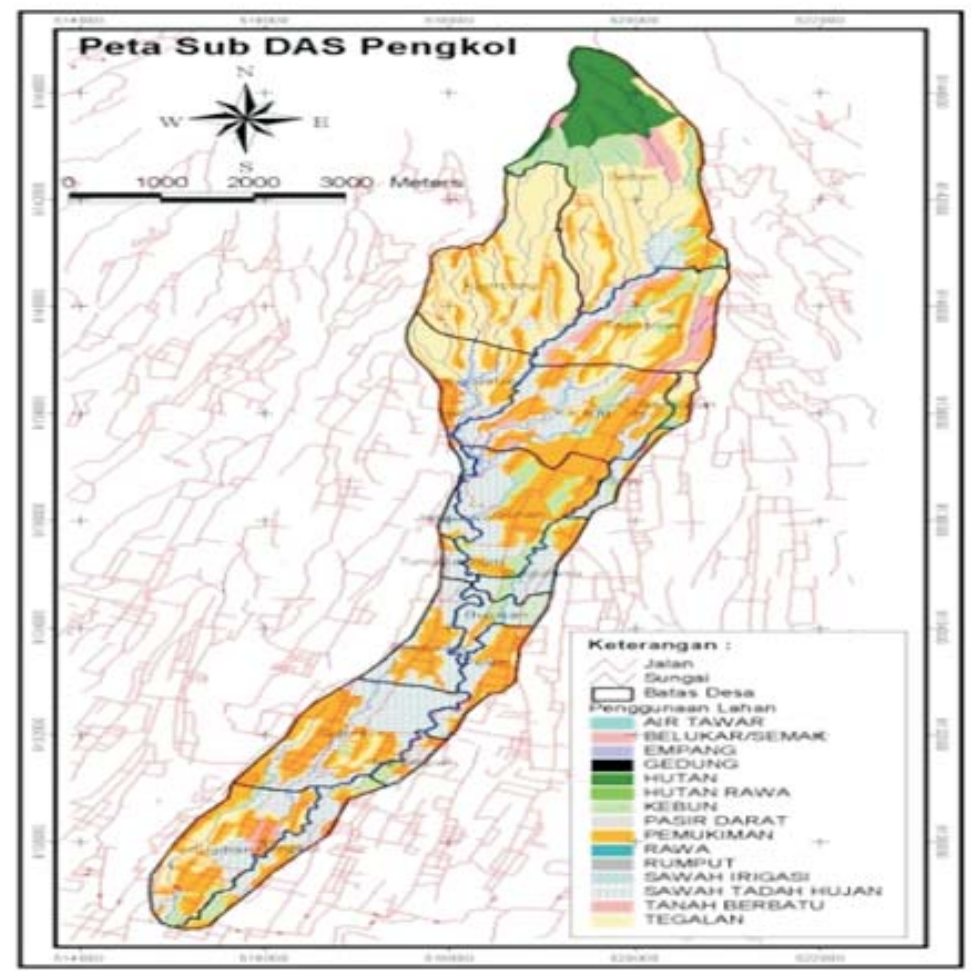

Gambar 1. Lokasi Penelitian di Sub Das Pengkol

Figure 1. Research Sites in Sub-Watershed Pengkol

\section{HASIL DAN PEMBAHASAN}

\section{A. Gambaran Umum Wilayah Penelitian}

Sub DAS Pengkol terletak pada garis lintang $7^{0} 32^{\prime}-8^{0} 15^{\prime}$ LS dan garis bujur $110^{\circ} 41^{\prime}-111^{\circ} 18^{\prime}$ BT dengan luas 3.057,59 Ha. Sub DAS Pengkol secara administratif masuk di Kabupaten Wonogiri. Kabupaten Wonogiri terbagi menjadi 25 kecamatan dengan luas wilayah 182.236,0236 Ha. Keadaan alamnya sebagian besar terdiri dari pegunungan yang berbatu gamping, terutama di bagian selatan, termasuk jajaran Pegunungan Seribu yang merupakan sumber mata air bagi Sungai Bengawan Solo.

Berdasarkan data tahun 2006-2010 jumlah penduduk Kabupaten Wonogiri rata-rata berjumlah 1.200.500 jiwa terdiri laki-laki 602.314 jiwa dan perempuan 598.186 jiwa dengan kepadatan penduduk adalah 659,76 jiwa $/ \mathrm{km}^{2}$, pertumbuhan penduduk sebesar 2,67\%. PDRB tahun 2001-2010 berdasarkan harga berlaku adalah Rp 3.490.426,14 juta didominasi oleh sektor pertanian $51 \%$, jasa $13 \%$, perdagangan, hotel dan resto $12 \%$. PDRB berdasarkan harga konstan adalah Rp. 1.901.402 juta.
Berdasarkan data tahun 2008 rata-rata produksi sawah mengalami kenaikan dari 53,90 kw/ha menjadi 56,09 $\mathrm{kw} / \mathrm{ha}$ dan padi gogo dari 31,20 $\mathrm{kw} / \mathrm{ha}$ menjadi $32,89 \mathrm{kw} / \mathrm{ha}$. Untuk palawija rata-rata produksi masing-masing komoditi mengalami penurunan. Ketersediaan pangan untuk padi dan jagung surplus masing-masing sebesar 58.484 ton padi dan 232.985 ton jagung.

Kondisi penutupan lahan sub DAS Pengkol didominasi oleh sawah $29,30 \%$, tegal $27,80 \%$ dan pemukiman $25,86 \%$. Secara lebih jelas dapat dilihat pada Tabel 1.

Contoh kasus di Desa Kembang, Kecamatan Jatipurno, menurut petani pada saat musim hujan, tanah selalu mengalami erosi yang tinggi, sehingga banyak sedimen yang terlarut dalam sungai dan bermuara di Sub DAS Keduang. Desa Kembang merupakan salah satu penyumbang sedimen terbesar di Sub DAS Keduang. Oleh karena itu, desa tersebut dijadikan proyek penghijauan oleh PT Bakti Usaha Menanam Nusantara Hijau Lestari II (PT BUMN HL II). PT BUMN HL II tersebut merupakan anak perusahaan BUMN di bidang agroindustri yang dimodali secara konsorsium oleh PT Perkebunan Nusantara (PTPN) IX, PTPN X, 
PTPN XI, PTPN XII, Perum Perhutani, PT Petrokimia Gresik, PT Rajawali Indonesia, dan Perum Jasa Tirta I. Perusahaan patungan tersebut bergerak dalam agrobisnis dan agroindustri berbasis pelestarian lingkungan.

Kondisi lahan dengan kelerengan yang curam menyebabkan tanah mudah tererosi, sehingga proyek penghijauan ini diharapkan dapat menanggulangi erosi yang tinggi di Desa Kembang. Jenis tanaman penghijauan ini adalah tanaman karet, sengon salomon dan jabon. Sementara itu tanaman dibawah tegakannya adalah kunyit, serai wangi dan tanaman palawija. Petani diberi kebebasan memilih jenis tanaman keras maupun tanaman di bawah tegakan yang akan ditanam. Pupuk, HOK dan bibit berasal dari PT BUMN HL II, dengan sharing 60\% untuk petani dan $40 \%$ untuk PT BUMN HL II. Selain Desa Kembang, desa lain yang menjadi sasaran adalah Desa Girimulyo dan Desa Balepanjang, Kecamatan Jatipurno.

Tabel 1. Penutupan Lahan di Sub DAS Pengkol

Table 1. Land Cover in Pengkol Sub-Watershed

\begin{tabular}{lrr}
\hline \multicolumn{1}{c}{ Penutupan lahan (land cover) } & Luas (broad) Ha & \multicolumn{2}{c}{$\%$} \\
\hline Hutan (forest) & 1441,954 & 4,64 \\
Kebun (garden) & 270,066 & 8,83 \\
Semak (shrubbery) & 108,589 & 3,55 \\
Lapangan (field) & 0,171 & 0,01 \\
Sawah (rice field) & 895,815 & 29,30 \\
Air tawar (freshwater) & 0,353 & 0,01 \\
Tegal (dry fields) & 850,044 & 27,80 \\
Pemukiman (settlement) & 790,634 & 25,86 \\
\hline Jumlah (amount) & 3057,586 & 100,00 \\
\hline
\end{tabular}

Sumber (Source): Analisis data primer 2010 (Primary analysis 2010)

\section{B. Kondisi Sosial Ekonomi dan Budaya}

\section{Karakteristik Responden}

Responden di Sub DAS Pengkol di ketiga desa rata-rata dalam usia produktif yaitu 44 tahun sampai dengan 52 tahun; dengan pekerjaan tetap didominasi pertanian dan pekerjaan sampingan adalah pertanian, perdagangan dan pertukangan; pendidikan rata-rata SD dan SMP, dengan tanggungan keluarga rata-rata empat orang. Responden yang diwawancarai adalah dari masyarakat biasa, pamong desa dan ketua kelompok tani. Setiap responden minimal mempunyai lahan milik tegal. Secara lebih jelas dapat dilihat pada Tabel 2 dan Tabel 3.

Tabel 2. Karakteristik Responden di Sub DAS Pengkol (Umur, Pekerjaan Tetap dan Pekerjaan Sampingan) Table 2. Characteristics of Respondents in Pengkol Sub-Watershed (Age, Permanent Jobs and Secondary Job)

\begin{tabular}{|c|c|c|c|c|c|c|c|c|c|c|c|c|c|c|c|}
\hline \multirow{2}{*}{$\begin{array}{l}\text { No } \\
\text { (No) }\end{array}$} & \multirow{2}{*}{$\begin{array}{l}\text { Desa (village) } \\
\text { Kecamatan } \\
\text { (sub district) }\end{array}$} & \multirow{2}{*}{$\begin{array}{l}\text { DAS } \\
\text { Keduang } \\
\text { (watershed } \\
\text { keduang) }\end{array}$} & \multirow{2}{*}{$\begin{array}{l}\text { Umur } \\
\text { Rerata (Th) } \\
\text { (mean age) } \\
\text { (year) }\end{array}$} & \multicolumn{6}{|c|}{ Pekerjaan Tetap (permanent job) } & \multicolumn{6}{|c|}{ Pekerjaan Sampingan (secondary job) } \\
\hline & & & & $\begin{array}{l}\text { Tani } \\
\text { (farmer) }\end{array}$ & $\begin{array}{l}\text { Buruh } \\
\text { (labor) }\end{array}$ & $\begin{array}{l}\text { PNS } \\
\text { (civil } \\
\text { servant) }\end{array}$ & $\begin{array}{l}\text { Dagang } \\
\text { (trade) }\end{array}$ & $\begin{array}{l}\text { Tukang } \\
\text { (handyman)) }\end{array}$ & $\begin{array}{l}\text { Lainnya } \\
\text { (Other) }\end{array}$ & $\begin{array}{l}\text { Tani } \\
\text { (farmer) }\end{array}$ & $\begin{array}{l}\text { Buruh } \\
\text { (labor) }\end{array}$ & $\begin{array}{l}\text { Dagang } \\
\text { (trade) }\end{array}$ & $\begin{array}{l}\text { Swsta } \\
\text { (private } \\
\text { sector) }\end{array}$ & $\begin{array}{l}\text { Tukang } \\
\text { (handyman)) }\end{array}$ & $\begin{array}{l}\text { Lainnya } \\
\text { (Other) }\end{array}$ \\
\hline 1 & & & 44 & & & & & & & & & & & & \\
\hline 2 & Karang, Slogohimo & Tengah & 50 & & $6 \%$ & & & & & & & & & & \\
\hline 3 & & Hilir & & & $0 \%$ & & & & & & $11 \%$ & & & & $22 \%$ \\
\hline
\end{tabular}

Sumber (Source): Analisis Data Primer 2010 (Primary data analysis 2010) 
Tabel 3. Karakteristik Responden (Pendidikan, Tanggungan Keluarga, Status dalam Masyarakat) Table 3. Respondent characteristics (Education, Family Dependents, Status in Society)

\begin{tabular}{|c|c|c|c|c|c|c|c|c|c|c|c|c|c|c|}
\hline \multirow{2}{*}{$\begin{array}{l}\text { No } \\
\text { (No) }\end{array}$} & \multirow{2}{*}{$\begin{array}{l}\text { Desa (village) } \\
\text { Kecamatan } \\
\text { (sub district) }\end{array}$} & \multirow{2}{*}{$\begin{array}{l}\text { DAS } \\
\text { Keduang } \\
\text { (watersbed } \\
\text { keduang) }\end{array}$} & \multicolumn{6}{|c|}{ Pendidikan (education) } & \multirow{2}{*}{$\begin{array}{c}\text { Tanggungan } \\
\text { Keluarga } \\
\text { (org/KK) } \\
\text { (family dependent) }\end{array}$} & \multicolumn{5}{|c|}{ Status dalam masyarakat (status in society) } \\
\hline & & & $\begin{array}{l}\text { TS } \\
(n o \\
\text { school }) \\
\end{array}$ & $\begin{array}{c}\text { SD } \\
\text { (primary } \\
\text { school) } \\
\end{array}$ & $\begin{array}{c}\text { TT SD } \\
\text { (not complete } \\
\text { primary school) }\end{array}$ & $\begin{array}{c}\text { SMP } \\
\text { (junior bigh } \\
\text { school) }\end{array}$ & $\begin{array}{l}\text { SMA } \\
(\text { bigh } \\
\text { school }) \\
\end{array}$ & $\begin{array}{l}\text { D3/PT } \\
\text { (collegere) }\end{array}$ & & $\begin{array}{c}\text { Biasa } \\
\text { (ordinary) }\end{array}$ & $\begin{array}{l}\text { Pamong } \\
\text { (pamong) }\end{array}$ & $\begin{array}{c}\mathrm{RT} / \mathrm{RV} / \mathrm{Kadus} \\
(\mathrm{RT} / \mathrm{RW} \mid \\
\mathrm{Kaddus}) \\
\end{array}$ & $\begin{array}{c}\text { Ketua Klpk Tani } \\
\text { (Chairman of } \\
\text { Farmers Group) }\end{array}$ & $\begin{array}{l}\text { Lainnya } \\
\text { (others) }\end{array}$ \\
\hline 1 & Setren, Slogohimo & Hulu & $11 \%$ & $22 \%$ & $0 \%$ & $50 \%$ & $11 \%$ & $6 \%$ & $4,3 \%$ & $22 \%$ & $11 \%$ & $50 \%$ & $11 \%$ & $11 \%$ \\
\hline 2 & Karang, Slogohimo & Tengah & $13 \%$ & $19 \%$ & $13 \%$ & $31 \%$ & $19 \%$ & $6 \%$ & $4,5 \%$ & $56 \%$ & $6 \%$ & $19 \%$ & $13 \%$ & $6 \%$ \\
\hline 3 & Sugihan, Jatiroto & Hilir & $0 \%$ & $61 \%$ & $6 \%$ & $22 \%$ & $0 \%$ & $6 \%$ & $4,3 \%$ & $33 \%$ & $6 \%$ & $17 \%$ & $22 \%$ & $17 \%$ \\
\hline
\end{tabular}

Sumber (Source): Analisis Data Primer 2010 (Primary data analysis 2010)

Berdasarkan Tabel 2 terlihat pekerjaan tetap dan pekerjaan sampingan masyarakat baik di daerah hulu sampai hilir adalah petani. Pada Tabel 1, dijelaskan pula bahwa penutupan lahan di DAS Pengkol didominasi sawah dan tegal. Hal ini menunjukkan bahwa telah terjadi eksploitasi lahan, baik di daerah hulu maupun daerah hilir dari Sub DAS Keduang. Eksploitasi lahan yang berlebihan inilah yang dapat menimbulkan erosi dan sedimentasi di Waduk Gadjah Mungkur, sehingga diperlukan pengalihan pekerjaan diluar lahan pertanian.

Berdasarkan Tabel 3, terlihat pendidikan ratarata dari responden adalah berpendidikan SD sampai SMP, meskipun ada beberapa yang berpendidikan SMA dan perguruan tinggi. Pendidikan responden rata-rata rendah, yang tentu saja ini akan sangat mempengaruhi dalam berpikir, begitu juga dalam menerima hal-hal baru (Tribun News, 2011). Pendidikan yang rendah ini bisa disebabkan karena tingkat kesadaran masyarakat untuk bersekolah masih rendah atau kurangnya biaya untuk bersekolah.

\section{Kepemilikan Lahan}

Petani di Sub DAS Pengkol rata-rata memiliki lahan lebih dari satu bidang lahan. Minimal petani memiliki lahan tegal dan pekarangan. Rata-rata petani secara keseluruhan baik itu lahan tegal, sawah, pekarangan, dan lahan hutan mempunyai luas 0,33 Ha. Kepemilikan lahan mereka rata-rata sempit, apalagi rata-rata petani mempunyai tanggungan keluarga 4 orang.

Tanaman yang dibudidayakan adalah tanaman yang nilai ekonominya masih rendah, seperti jagung, ketela pohon, empon-empon dan lain sebagainya. Hasil panen hanya untuk memenuhi kebutuhan primer rumah tangga seperti makan, dan hanya sedikit panen yang dapat dijual. Secara lebih lengkap dapat dilihat pada Tabel 4.

\section{Sosial, Budaya, Nilai Tradisional dan Kelembagaan}

Kondisi sosial budaya, nilai tradisional dan kelembagaan di Sub DAS Pengkol secara jelas dapat dilihat pada Tabel 5 .

Tabel 4. Rata-rata Kepemilikan Lahan setiap Kepala Keluarga petani di Sub DAS Pengkol Table 4. Land Tenure Average of each head of family farmer in Pengkol Sub-Watershed

\begin{tabular}{llccccc}
\hline \multirow{2}{*}{$\begin{array}{c}\text { No } \\
\text { No) }\end{array}$} & $\begin{array}{c}\text { Desa (village) } \\
\text { Kecamatan } \\
\text { (sub district) }\end{array}$ & $\begin{array}{c}\text { Tegal } \\
\text { (dry land) }\end{array}$ & $\begin{array}{c}\text { Hutan } \\
\text { (forest) }\end{array}$ & $\begin{array}{c}\text { Sawah } \\
\text { (paddy field) }\end{array}$ & $\begin{array}{c}\text { Pekarangan } \\
\text { (grounds) }\end{array}$ & $\begin{array}{c}\text { Rata-rata } \\
\text { (average) }\end{array}$ \\
\hline 1 & $\begin{array}{l}\text { Desa Setren, } \\
\text { Kec Slogohimo }\end{array}$ & 0,42 & 0,30 & 0,36 & 0,40 & 0,35 \\
2 & $\begin{array}{l}\text { Desa Karang, } \\
\text { Kec Slogohimo }\end{array}$ & 0,37 & - & 0,23 & 0,46 & 0,37 \\
\hline & $\begin{array}{l}\text { Desa Sugihan, } \\
\text { Kec Jatiroto }\end{array}$ & 0,40 & - & 0,26 & 0,18 & 0,28 \\
\hline & Rata-rata (average) & 0,39 & 0,10 & 0,28 & 0,35 & 0,33 \\
\hline
\end{tabular}

Sumber (Source): Analisis data primer 2010 (Primary data analysis 2010) 
Tabel 5. Kondisi Sosial Budaya, Nilai Tradisional dan Kelembagaan di Sub DAS Pengkol

Table 5. Socio-Cultural, Traditional Values and Institutions in Pengkol Sub-Watershed

\begin{tabular}{|c|c|c|c|c|}
\hline No & $\begin{array}{c}\text { Uraian } \\
\text { (description) }\end{array}$ & $\begin{array}{l}\text { Desa (village) Setren, Kec } \\
\text { (sub district) Slogohimo }\end{array}$ & $\begin{array}{l}\text { Desa (village) Karang, Kec } \\
\text { (sub district) Slogohimo }\end{array}$ & $\begin{array}{l}\text { Desa (village) Sugihan, } \\
\text { Kec (sub district) Jatiroto }\end{array}$ \\
\hline 1 & $\begin{array}{l}\text { Sosial dan } \\
\text { Budaya (social } \\
\text { and cultural) }\end{array}$ & 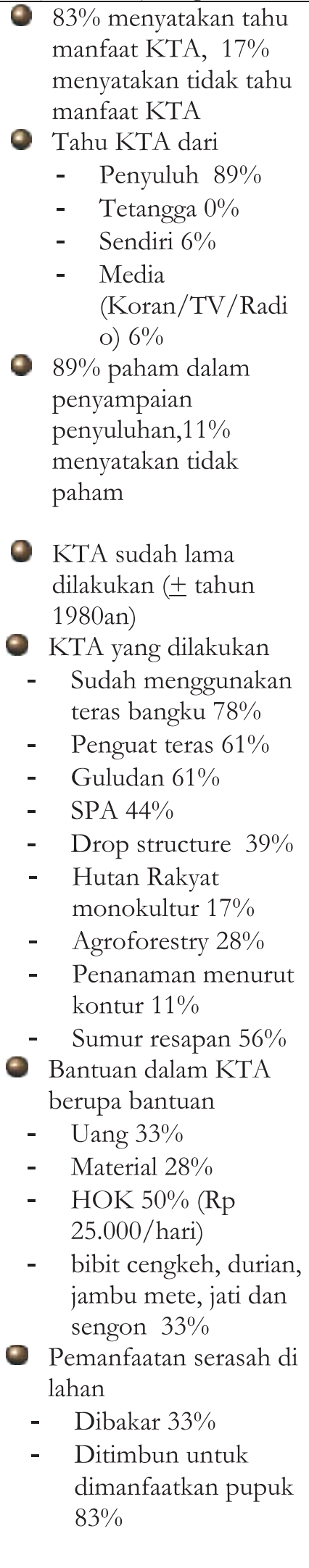 & 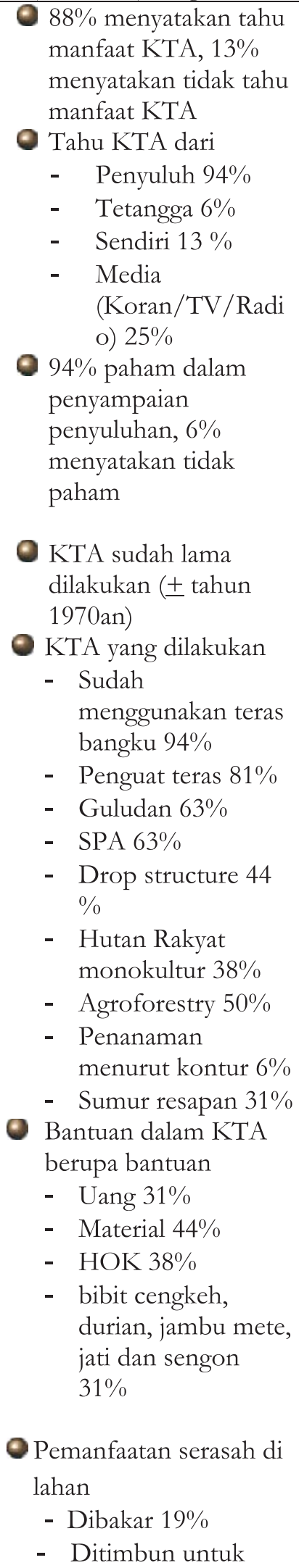 & 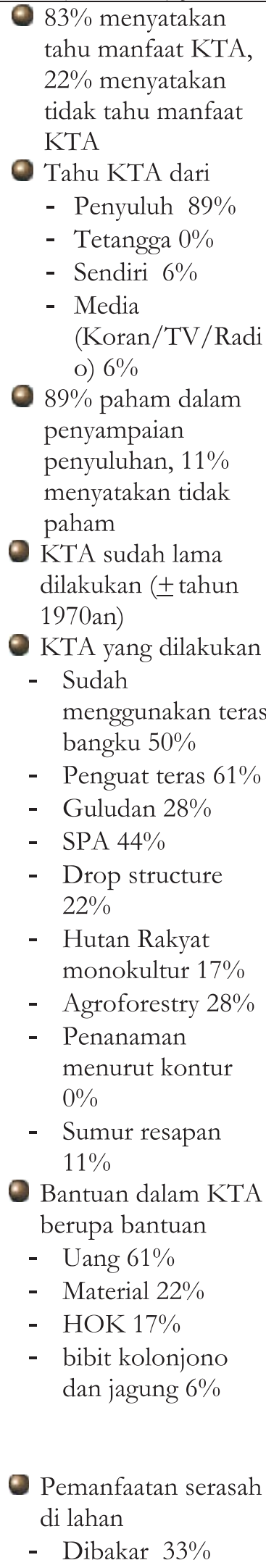 \\
\hline
\end{tabular}


Tabel 5. Lamjutan

Table 5. Continued

\begin{tabular}{|c|c|c|c|c|}
\hline No & $\begin{array}{c}\text { Uraian } \\
\text { (description) }\end{array}$ & $\begin{array}{c}\text { Desa (village) Setren, Kec } \\
\text { (sub district) Slogohimo }\end{array}$ & $\begin{array}{c}\text { Desa (village) Karang, Kec } \\
\text { (sub district) Slogohimo }\end{array}$ & $\begin{array}{l}\text { Desa (village) Sugihan, } \\
\operatorname{Kec} \text { (sub district) Jatiroto }\end{array}$ \\
\hline & & & $\begin{array}{l}\text { dimanfaatkan pupuk } \\
75 \%\end{array}$ & $\begin{array}{l}\text { - Ditimbun untuk } \\
\text { dimanfaatkan } \\
\text { pupuk } 56 \%\end{array}$ \\
\hline 2 & $\begin{array}{l}\text { Nilai } \\
\text { Tradisional } \\
\text { (traditional values) }\end{array}$ & $\begin{array}{l}\text { Budaya dan adat belum } \\
\text { ada, sehingga jika ada } \\
\text { masyarakat yang tidak } \\
\text { melakukan konservasi, } \\
\text { tidak ada sangsinya } \\
\text { atau dibiarkan saja } \\
\text { Budaya masih } \\
\text { berhubungan dengan } \\
\text { gotong royong bersih } \\
\text { desa, selamatan jika } \\
\text { panen raya. } \\
\text { Budaya yang } \\
\text { berhubungan dengan } \\
\text { konservasi tanah dan } \\
\text { air belum ada }\end{array}$ & $\begin{array}{l}\text { Budaya dan adat masih } \\
\text { bersifat kegiatan } \\
\text { gotong royong pada } \\
\text { saat pengolahan tanah } \\
\text { dan membuat } \\
\text { konservasi bagi petani } \\
\text { yang belum membuat. } \\
\text { Jika ada masyarakat } \\
\text { yang tidak melakukan } \\
\text { konservasi, tidak ada } \\
\text { sangsinya karena akan } \\
\text { dibuat secara } \\
\text { bergotong royong }\end{array}$ & $\begin{array}{l}\text { Budaya dan adat } \\
\text { masih bersifat } \\
\text { kegiatan gotong } \\
\text { royong pada saat } \\
\text { pengolahan tanah } \\
\text { dan membuat } \\
\text { konservasi bagi } \\
\text { petani yang belum } \\
\text { membuat. } \\
\text { Jika ada masyarakat } \\
\text { yang tidak melakukan } \\
\text { konservasi, tidak ada } \\
\text { sangsinya karena } \\
\text { akan dibuat secara } \\
\text { bergotong royong }\end{array}$ \\
\hline 3 & $\begin{array}{l}\text { Kelembagaan } \\
\text { (institutional) }\end{array}$ & $\begin{array}{l}\text { Kegiatan kelembagaan } \\
\text { yang terkait dengan } \\
\text { konservasi tanah yaitu } \\
\text { KKTA (Kelompok } \\
\text { Konservasi Tanah dan } \\
\text { Air), masih didominasi } \\
\text { dengan kegiatan arisan. }\end{array}$ & $\begin{array}{l}\text { Kegiatan kelembagaan } \\
\text { yang terkait dengan } \\
\text { konservasi tanah yaitu } \\
\text { KKTA (Kelompok } \\
\text { Konservasi Tanah dan } \\
\text { Air). Sebagai stimulus } \\
\text { agar petani datang } \\
\text { dilakukan kegiatan } \\
\text { arisan. }\end{array}$ & $\begin{array}{l}\text { Kegiatan } \\
\text { kelembagaan yang } \\
\text { terkait dengan } \\
\text { konservasi tanah } \\
\text { adalah kegiatan } \\
\text { kelompok tani. } \\
\text { Kegiatannya berupa } \\
\text { arisan dan } \\
\text { penyuluhan }\end{array}$ \\
\hline
\end{tabular}

Sumber (Source): Analisis Data Primer 2010 (Primary data analysis 2010)

Berdasarkan Tabel 5, pemahaman petani akan konservasi tanah dan air pada umumnya sudah baik. Menurut petani, manfaat konservasi tanah dan air adalah sebagai berikut : (1) dapat mengurangi erosi dan sedimentasi, (2) menjaga kelestarian alam, (3) dapat memelihara tanah, (4) menjaga kesuburan dan keawetan tanah, (5) mencegah sedimentasi yang berlebihan dari waduk Gajah Mungkur, (6) dapat menyimpan air, (7) meningkatkan hasil produksi pertanian.

Sementara itu ada juga petani yang tidak tahu manfaat konservasi tanah dan air. Dilihat dari prosentase yang paham dan yang tidak paham akan masalah konservasi tanah dan air, kurang lebih 83\%-88\% petani paham dan hanya sebagian kecil saja yang tidak paham. Hal ini dikarenakan petani tersebut tidak aktif mengikuti pertemuan rutin di desanya atau petani tersebut tidak pernah memperbarui informasi tentang pertanian. Di ketiga desa tersebut sudah dilakukan kegiatan pertemuan setiap bulan untuk memberi penyuluhan oleh penyuluh dan ketua kelompok tani. Materi penyuluhan yang disampaikan meliputi: (1) cara mengolah dan memelihara lahan agar tanah tidak banyak terbawa air (erosi), (2) cara membuat teras, (3) cara mengelola dan memanfaatkan lahan secara baik, (4) cara mengendalikan erosi dan sedimentasi dengan sipil teknis dan vegetative, membuat saluran air dan sengkedan, (5) penanaman tanaman keras, (6) pembuatan SPA, tampingan teras ditanami rumput, (7) pentingnya pupuk organik, (8) mengoptimalkan lahan dengan ditanami tanaman keras dan buah-buahan, (9) macammacam teknik konservasi, (10) penanggulangan hama dan penyakit, (11) pembuatan teras dan biopori untuk menahan laju erosi dan penyelamatan air, (12) penanaman rumput gajah, (13) cara membuat pupuk. 
Kondisi air minum di ketiga desa tersebut dalam keadaan baik, ini dilihat dari kelestarian pasokan air sepanjang tahun dan kondisi air yang jernih, sehingga kebutuhan air bersih di DAS Pengkol masih terpenuhi. Pada umumnya sumber air minum tersebut berasal dari sumur dan mata air. Di Desa Setren (hulu) dan Desa Karang (tengah) sumber air minum berasal dari sumber mata air sedangkan Desa Sugihan (hilir) berasal dari sumur.

\section{Pendapatan Keluarga}

Pendapatan keluarga di ketiga desa di Sub DAS Pengkol pada umumnya hampir sama yaitu diperoleh dari usaha tani dan luar usaha tani. Pendapatan dari usaha tani paling tinggi adalah Desa Sugihan, sedangkan pendapatan secara keseluruhan (mempertimbangkan pendapatan dari luar usaha tani) adalah Desa Karang. Pendapatan ini sudah dapat untuk memenuhi kebutuhan hidup layak petani, dimana Kebutuhan Hidup Layak Kabupaten Wonogiri adalah Rp. 772.931,00/ bulan/KK (BPS,2010). Untuk memenuhi kebutuhan sehari-hari, petani rata-rata mempunyai pekerjaan sampingan seperti buruh, tukang, pedagang dan lain-lain. Secara lebih jelas dapat di lihat pada Tabel 6 .

Tabel 6. Rata-rata Pendapatan Keluarga di Sub DAS Pengkol

Table 6. Average Family Income in Sub-Watershed Pengkol

\begin{tabular}{|c|c|c|c|c|c|c|c|c|c|c|}
\hline \multirow[t]{2}{*}{ No } & \multirow{2}{*}{$\begin{array}{c}\text { Desa } \\
\text { (village), } \\
\text { Kecamatan } \\
\text { (sub district), } \\
\text { Kabupaten } \\
\text { (regency) }\end{array}$} & \multicolumn{3}{|c|}{$\begin{array}{c}\text { Rata-rata Pendapatan } \\
\text { (average income) }\end{array}$} & \multicolumn{3}{|c|}{$\begin{array}{c}\text { Rata-rata Pengeluaran } \\
\text { (average expenditure) }\end{array}$} & \multirow[b]{2}{*}{$\begin{array}{l}\text { Pendapatan } \\
\text { Dari UT } \\
\text { (farm income) }\end{array}$} & \multirow{2}{*}{$\begin{array}{l}\text { Pendapatan } \\
\text { bersih/ } \\
\text { tahun (net } \\
\text { income/year) }\end{array}$} & \multirow{2}{*}{$\begin{array}{c}\text { Pendapatan } \\
\text { bersih/bulan } \\
\text { (net income/ } \\
\text { month) }\end{array}$} \\
\hline & & $\begin{array}{l}\text { Usaha tani } \\
\text { (farming) }\end{array}$ & $\begin{array}{c}\text { Luar } \\
\text { Usaha Tani } \\
\text { (non } \\
\text { farming) }\end{array}$ & $\begin{array}{l}\text { Total } \\
\text { (amount) }\end{array}$ & $\begin{array}{l}\text { Usaha tani } \\
\text { (farming) }\end{array}$ & $\begin{array}{l}\text { Rumah } \\
\text { tangga } \\
\text { (housebold) }\end{array}$ & $\begin{array}{l}\text { Total } \\
\text { (amount) }\end{array}$ & & & \\
\hline 1 & $\begin{array}{l}\text { Setren, } \\
\text { Slogohimo, } \\
\text { Wonogiri }\end{array}$ & 30.886 .401 & 8.935 .067 & 39.821 .467 & 9.031 .191 & 10.448 .563 & 19.479 .754 & 21.855 .210 & 20.341 .714 & 1.695 .143 \\
\hline 2 & $\begin{array}{l}\text { Karang, } \\
\text { Slogohimo, } \\
\text { Wonogiri }\end{array}$ & 27.211 .308 & 13.666 .667 & 40.877 .239 & 10.373 .167 & 10.373 .167 & 18.765 .405 & 18.819 .069 & 22.112 .569 & 1.842 .714 \\
\hline 3 & $\begin{array}{l}\text { Sugihan, } \\
\text { Jatiroto, } \\
\text { Wonogiri }\end{array}$ & 39.820 .810 & 8.981 .667 & 48.802 .477 & 16.482 .877 & 11.200 .075 & 27.682 .952 & 23.337 .933 & 21.119 .525 & 1.759 .960 \\
\hline
\end{tabular}

Sumber (Source): Analisis Data Primer 2010 (Primary data analysis 2010)

Pendapatan dari usaha tani diperoleh dari lahan tegal, sawah, hutan dan pekarangan. Pada lahan tegal didominasi tanaman padi, jagung dan ketela pohon. Padi dan jagung ditanam dua kali musim tanam, setelah itu lahan diberokan. Ketela pohon di Sub DAS Pengkol baru bisa dipanen setelah berumur dua tahun. Pada umumnya ketela pohon sudah dapat dipanen pada saat tanaman sudah berumur 9 (sembilan) bulan. Hal ini menunjukkan bahwa kondisi tanah sudah menurun kesuburannya.

Sawah tadah hujan ditanam dua kali musim tanam dan sawah irigasi ditanam tiga kali musim tanam. Di lahan pekarangan biasanya ditanami tanaman kayu-kayuan seperti jati, mahoni, bambu dan tanaman buah seperti mangga, pisang, mlinjo dan lainnya. Petani juga sudah memanfaatkan galengan dengan ditanami tanaman kacang panjang. Hasil panen dari lahan mereka lebih banyak dikonsumsi sendiri terutama padi. Untuk jagung dan ketela pohon biasanya sebagian dijual dan sebagian lagi dimakan sendiri sebagai campuran beras. Jagung dibuat nasi jagung, sedangkan untuk ketela pohon dibuat gaplek.

Tanaman kayu-kayuan seperti jati dan bambu, biasanya ditebang untuk memenuhi kebutuhan sendiri seperti untuk membangun rumah, sementara itu bambu biasanya untuk membuat kandang ternak. Mereka jarang menjual kayu dan bambu karena mereka menanam hanya untuk memenuhi kebutuhannya sendiri. Secara lebih jelas pola tanam dari setiap musim tanam pada setiap lahan dapat dilihat pada Tabel 7. 
Tabel 7. Jenis Tanaman yang di Tanam di Lahan Milik Petani di Sub DAS Pengkol

Table 7. Crops Planted in the Owned Land Farmers in Pengkol Sub-Watershed

\begin{tabular}{|c|c|c|c|c|c|}
\hline \multirow{2}{*}{$\begin{array}{l}\text { No } \\
\text { (No) }\end{array}$} & \multirow{2}{*}{$\begin{array}{l}\text { Desa(village) } \\
\text { Kecamatan } \\
\text { (sub district) }\end{array}$} & \multirow{2}{*}{$\begin{array}{l}\text { Jenis Lahan } \\
\text { (types of land) }\end{array}$} & \multicolumn{3}{|c|}{ Jenis Tanaman (types of crops) } \\
\hline & & & $\begin{array}{l}\text { Musim Tanam } 1 \\
\text { (cropping season 1) }\end{array}$ & $\begin{array}{l}\text { Musim Tanam } 2 \\
\text { (cropping season 2) }\end{array}$ & $\begin{array}{l}\text { Musim Tanam } 3 \\
\text { (cropping season 3) }\end{array}$ \\
\hline \multirow[t]{6}{*}{1} & \multirow[t]{6}{*}{$\begin{array}{l}\text { Setren, } \\
\text { Slogohimo }\end{array}$} & \multirow[t]{2}{*}{ Tegal } & $\begin{array}{l}\text { Jagung, buncis, ketela } \\
\text { pohon, bawang merah, } \\
\text { bawang putih }\end{array}$ & $\begin{array}{l}\text { Ketela pohon, } \\
\text { tembakau, wortel, } \\
\text { buncis, kacang } \\
\text { panjang, padi, } \\
\text { bawang merah }\end{array}$ & Ketela pohon \\
\hline & & & \multicolumn{3}{|c|}{$\begin{array}{l}\text { Cengkeh, alpukat, nangka, petai, durian, puspa, sengon, mahoni, jati, } \\
\text { rambutan, durian }\end{array}$} \\
\hline & & Hutan & Buncis, kentang & Tembakau & wortel, jagung \\
\hline & & Sawah & Padi, jagung & Padi & padi \\
\hline & & \multirow[t]{2}{*}{ Pekarangan } & $\begin{array}{l}\text { Jagung, buncis, kacang } \\
\text { tanah, tembakau }\end{array}$ & $\begin{array}{l}\text { Ketela pohon, } \\
\text { buncis, kacang } \\
\text { panjang }\end{array}$ & kunyit \\
\hline & & & \multicolumn{3}{|c|}{ Mahoni, jati, sengon, petai, cengkeh, durian, nangka, mlinjo, kelapa } \\
\hline \multirow[t]{6}{*}{2} & \multirow[t]{6}{*}{$\begin{array}{l}\text { Karang, } \\
\text { Slogohimo }\end{array}$} & \multirow[t]{2}{*}{ Tegal } & $\begin{array}{l}\text { Jagung, padi, ketela } \\
\text { pohon, }\end{array}$ & \multicolumn{2}{|l|}{$\begin{array}{l}\text { Ketela pohon, } \\
\text { kacang panjang, } \\
\text { kunyit }\end{array}$} \\
\hline & & & \multicolumn{3}{|c|}{ Sengon, jati, mahoni, cengkeh, jambu mete, kelapa, petai, kakao } \\
\hline & & Hutan & \multicolumn{3}{|c|}{ Menyadap pinus } \\
\hline & & Sawah & $\begin{array}{l}\text { Padi, jagung, ketela } \\
\text { pohon }\end{array}$ & Padi & padi \\
\hline & & \multirow[t]{2}{*}{ Pekarangan } & $\begin{array}{l}\text { Jagung, ketela pohon, } \\
\text { kacang panjang, jahe, } \\
\text { kunyit, kedelai }\end{array}$ & Ketela pohon & Ketela pohon \\
\hline & & & Kelapa, sengon, jati, n & $\begin{array}{l}\text { ahoni, cengkeh, durian, } \\
\text { pukat, kopi, rambutan }\end{array}$ & petai, kakao, mlinjo, \\
\hline \multirow[t]{5}{*}{3} & \multirow[t]{5}{*}{$\begin{array}{l}\text { Sugihan, } \\
\text { Jatiroto }\end{array}$} & \multirow[t]{2}{*}{ Tegal } & $\begin{array}{l}\text { Jagung, ketela pohon, } \\
\text { padi, kacang panjang }\end{array}$ & $\begin{array}{l}\text { Padi, kacang panjang, } \\
\text { kedelai, jagung }\end{array}$ & \\
\hline & & & \multicolumn{3}{|c|}{ Jambu mete, bambu, jati, mahoni } \\
\hline & & Sawah & $\begin{array}{l}\text { Padi, jagung, kacang } \\
\text { panjang, terong, bayam }\end{array}$ & $\begin{array}{l}\text { Padi, kacang panjang, } \\
\text { jagung }\end{array}$ & $\begin{array}{l}\text { Padi, kedelai, kacang } \\
\text { panjang, cabe }\end{array}$ \\
\hline & & \multirow[t]{2}{*}{ Pekarangan } & $\begin{array}{l}\text { Jagung, kunyit, ketela } \\
\text { pohon, kacang panjang }\end{array}$ & \multicolumn{2}{|l|}{ Kacang panjang } \\
\hline & & & $\begin{array}{r}\text { Jambu mete, pisang } \\
\text { sonoke }\end{array}$ & $\begin{array}{l}\text { jati, mahoni, rambutar } \\
\text { ing, johar, trembesi, m }\end{array}$ & $\begin{array}{l}\text { sengon, bambu, } \\
\text { ngga }\end{array}$ \\
\hline
\end{tabular}

Sumber (Source): Analisis Data Primer 2010 (Primary data analysis 2010) 


\section{Karakteristik Responden dalam Hubungan- nya dengan Pengelolaan DAS}

Karakteristik responden di daerah Sub DAS Pengkol pada umumnya adalah petani dengan usia produktif, mereka dapat diberdayakan untuk ikut serta dalam memperbaiki lingkungan. Secara umum mereka sudah memahami pentingnya konservasi, dan dampak yang diterima apabila tidak melakukan konservasi.

Menurut Suwarsono (2012) masyarakat merupakan pelaku sekaligus pengambil manfaat maupun dampak dalam pengelolaan sumberdaya alam di dalam suatu DAS. Sebagai pelaku yang aktif masyarakat mempunyai perilaku yang dapat mendukung upaya-upaya pengelolaan DAS, sebagai penikmat atau pengambil manfaat DAS yaitu pemanfaatan air permukaan dari sungai maupun sumur dibawah permukaan dan kesuburan tanah. Di lain pihak jika masyarakat memperburuk kondisi DAS, maka masyarakat akan menerima dampaknya.

Hal utama yang perlu dilakukan adalah menggerakkan petani dalam kegiatan-kegiatan terkait konservasi tanah. Masyarakat sebagai pemilik lahan berperan dalam mengelola lahan miliknya maupun sebagai pemegang keputusan mengubah fungsi lahannya (Suwarno, 2012). Dengan demikian masyarakat dapat mengolah tanah tanpa merusak lingkungan, mengkonservasi tanah secara baik sehingga dapat mengurangi erosi dan sedimentasi, serta menanam tanaman bernilai ekonomi tinggi. Selain itu perlu adanya kerjasama dengan pemuka masyarakat, instansi terkait, LSM dan yang berkepentingan dengan lingkungan dalam membangun daerah hulu. Hal ini karena pengelolaan daerah hulu (DAS hulu) tidak dapat dilakukan sendiri-sendiri.

Partisipasi aktif masyarakat tidak akan muncul tanpa disertai adanya pemberdayaan masyarakat berupa penciptaan kondisi yang memungkinkan masyarakat mampu membangun diri dan lingkungan secara mandiri. Hal lain yang tidak kalah pentingnya adalah perlu adanya penghargaan (reward) bagi masyarakat yang telah melakukan konservasi sesuai dengan kaedah konservasi sehingga masyarakat semakin terpacu untuk melakukan kegiatan-kegiatan yang dapat mengurangi erosi dan sedimentasi di daerah hulu.

\section{KESIMPULAN DAN SARAN}

1. Karakteristik masyarakat hulu pada umumnya adalah petani dengan umur produktif serta sudah paham akan manfaat dan dampak konservasi tanah.

2. Pada umumnya petani mempunyai lahan lebih dari satu bidang lahan yang luasnya sempit dan ditanami tanaman tumpangsari, empon-empon dan tanaman berkayu.

3. Pendapatan keluarga ketiga desa sudah berada diatas Kebutuhan Hidup Layak.

4. Perlu adanya pembinaan yang lebih baik dan terstruktur untuk membangun daerah hulu bersama masyarakat sehingga perlunya adanya kerjasama multipihak dari pemerintah, LSM, civitas akedemika dan instansi terkait lainnya untuk melakukan pemberdayaan masyarakat agar masyarakat lebih mandiri dan tidak tergantung hanya dari sektor pertanian saja.

5. Perlu adanya penghargaan (reward) untuk masyarakat hulu yang telah melakukan kegiatan konservasi tanah.

\section{DAFTAR PUSTAKA}

Atmojo, S.W. (2008). Peran agroforestry dalam menanggulangi banjir dan longsor $D A S$. Disajikan dalam Seminar Nasional Pendidikan Agroforestry Sebagai Strategi Menghadapi Pemanasan Global di Fakultas Pertanian, UNS. Solo, 4 Maret 2008. Www. Suntoro.staff.uns.ac.id / files/.../ 3agroforestri-banjir-dan-longsor-das.

Asdak, C. (2002). Hidrologi dan pengelolaan Daerah Aliran Sungai. Yogyakarta: Gadjah Mada University Press.

BPS. (2009). Kabupaten Wonogiri dalam angka. Wonogiri : BPS Kabupaten Wonogiri.

Departemen Kehutanan. (2009). Lampiran peraturan Direktur Jenderal Rehabilitasi Laban dan Perbutanan Sosial tentang Pedoman Monitoring dan Evaluasi Daerah Aliran Sungai No: P.04/V-SET/2009 Tanggal: 05 Maret 2009. Jakarta: Departemen Kehutanan. 
Departemen Kehutanan. (2009). Keputusan Menteri Kebutanan Republik Indonesia. Nomor SK.328/Menhut-II/2009. Tentang penetapan Daerah Aliran Sungai (DAS) dalam rangka Pembangunan Jangka Menengab (RPJM) Tahun 2010-2014. Jakarta : Departemen Kehutanan

Eka, K. I., \& S. Kukuh. (2008). Sedimentasi waduk dan kinerja Pemda. Wawasan, 6 Februari 2008.

Kartodihardjo, H., K. Murtilaksono, \& Untung, S. (2004). Institusi pengelolaan Daerah Aliran Sungai: konsep dan pengantar analisis kebijakan. Bogor : Fakultas Kehutanan, Institut Pertanian Bogor.

Paimin, Sukresno, \& Purwanto. (2006). Sidik cepat degradasi. Sub Daerah Aliran Sungai (Sub DAS). Pusat Penelitan dan Pengembangan Hutan dan Konservasi Alam. Bogor : Badan Penelitian dan Pengembangan Kehutanan.

Paimin, Sukresno, Tyas, M. B., \& Purwanto. (2002). Monitoring dan evaluasi Daerah Aliran Sungai dalam perspektif diagnosa kesehatannya. Prosiding Seminar Monitoring dan Evaluasi Pengelolaan DAS. Surakarta, 23 Desember 2002. Jakarta : Departemen Kehutanan.

Paimin. (2009). Laporan akbir hasil penelitian tabun 2003-2009. Usulan Kegiatan Hasil Penelitian (UKP). Sistem karakterisasi Daerah Aliran Sungai. Solo : Balai Penelitian Kehutanan Solo, Departemen Kehutanan.
Sarwono, \& Jonathan. (2006). Metode penelitian kuantitatif dan kualitatif. Yogyakarta: Graha Ilmu.

SCBFWM. (2013). Pengelolaan DAS berbasis masyarakat. Http://www.scbfwm. org/2013/02/13/pengelolaan-dasberbasis-masyarakat.html.

SCBFWM. (2010). Mengenal Daerah Aliran Sungai dan permasalahannya. proyek penguatan pengelolaan hutan dan DAS berbasis masyarakat. Buletin DAS nomor 1 September 2010. Http://www.Scbfwm.org.

Sejarah Waduk Gadjah Mungkur. (2012). Http://epriant.com /2012/01/ sejarahwaduk-gajah-mungkur.html.

Suwarno, J. (2012). Peran serta masyarakat dalam pengelolaan DAS. Buletin Bina DAS. September 2012. Http:/ / www.scbfwm.org.

Tim Peneliti BP2TPDAS-IBB. (2004). Pedoman Monitoring Dan Evaluasi Pengelolaan Daerah Aliran Sungai (edisi revisi 2004). Surakarta : BP2TPDAS- IBB Surakarta.

Tim Koordinasi Pengelolaan Sumber Daya Air. (2003). Pedoman teknis pengelolaan Daerah Aliran Sungai terpadu. Draft Final Sekretariat TKPSDA 2003. Www.Bappenas.go.id.

Tribun News. (2011). Tingkat pendidikan bisa mengendalikan penduduk. Jumat, 30 Desember 2011. http://m.tribunnews. com/2011/12/30/tingkat- pendidikanbisa-mengendalikan-penduduk. 